\title{
INTERNATIONAL HAPPINESS SCALE INTERVAL STUDY
}

\author{
Ruut Veenhoven \\ In: Alex C. Michalos (Ed.) Encyclopedia of Quality of Life and Well-Being Research \\ Springer, Dordrecht, Netherlands, 2014. Springer Reference Series, pp. 3323-3324. \\ ISBN 978-94-007-0752-8 \\ DOI: $10.1007 / 978-94-007-0753-5 \_3661$
}

\section{SYNONYMS}

Scale conversion; Scale transformation; Standardization of international happiness scale

\section{DEFINITION}

A research synthesis technique, which is used to convert responses to survey questions on happiness in different languages, using different verbal response scales, into a common 0-10 numerical scale.

\section{DESCRIPTION}

\subsection{Object}

This study is about survey questions on happiness using verbal response options, such as "very happy" and "fairly happy." The aim is to estimate what degrees of happiness are denoted by such terms as used in different questions and different languages. The degrees of happiness are expressed as numerical values on a 0-10 scale. The results are then used to compute comparable means and standard deviations. The goal is to enlarge the pool of data available for synthetic studies, in particular comparison of happiness across nations and over time.

\subsection{Method}

Native speakers read survey questions on happiness that had been used in their countries. For each separate question, they rate the relative value of each of the response options in their language. The native speakers do this using a computer. They are presented with a screen which shows a vertical bar scale, which they are asked to divide into sections by shifting separation lines. The possible response options with respect to happiness are presented next to the scale and move with the bars. The native speaker's task is to move the separation lines with the cursor until they feel that the intervals shown on the scale they have adjusted correspond with the degree of happiness denoted by each of the verbal response options. An example of the scale interval recorder is shown here. 


\subsection{Judges}

Rating in this study is done by volunteer university students recruited by participating professors. The judges rate response options to maximally 10 questions, a task that takes about 10 min. Given the precision required, at least 200 respondents per language are required. To date (2012), 41 of such studies have been completed in 13 languages.

\subsection{Application}

The results of these studies are used to calculate new averages and standard deviations from the available responses to survey questions on happiness that used verbal response options, and the transformed values are entered in the World Database of Happiness, next to the summary statistics obtained on the original response scale (Veenhoven, 2012).

Although originally developed for improving the comparison of results of happiness studies, this technique can also be used in other research fields where heterogeneous survey data needs to be converted into more homogenous scores.

\subsection{Documentation}

All details about this study are on the Web at http://worlddatabaseofhappiness.eur.nl/scale study/scale_fp.htm. This method is discussed in more detail in Veenhoven (2009) and Kalmijn et al. (2011). 


\section{REFERENCES}

Kalmijn, W., Arends, L., \& Veenhoven, R. (2011)

Happiness scale interval study: Methodological considerations.

Social Indicators Research, 102, 497-515.

Veenhoven, R. (2009)

International scale interval study: Improving the comparability of responses to survey questions about happiness. In M. Valerie \& H. Dennis (Eds.),

Quality of life and the millennium challenge: Advances in quality-of-life studies, theory and research (Social indicators research series, Vol. 35, pp. 45-58).

Dordrecht: Springer. ISBN e-ISBN 978-1-4020-8569-7.

Veenhoven, R. (2012)

World database of happiness, Archive of research findings on subjective enjoyment of life. Erasmus University Rotterdam, Netherlands.

\section{Cross References}

Happiness Measures 